\section{US space research}

\section{Moon beckons for NASA}

La Jolla, California

AFTER 15 years of coasting along with illdefined goals, the National Aeronautics and Space Administration (NASA) is setting its sights on a future which may include a return to the Moon.

Since President Reagan's State of the Union speech in January - when he approved the idea of a civilian space station and proposed his "star wars" defence - the agency has sponsored three study groups which asked "What should we do after the space station is built in 1992?"

The first met at Los Alamos in April. Called the Lunar Base Working Group, the 40 space experts in attendance concluded that the United States should return to the Moon. Their report to NASA, which will be released at a press conference in Washington, DC, in October, includes a list of scientific experiments that could be conducted on a lunar base. These include a radio telescope on the backside of the Moon which would not suffer electromagnetic interference from Earth and a laboratory for exploiting the Moon's vacuum.

The second, working under the rubric of a "Technological Springboard to the 21st Century", met for ten weeks at the California Space Institute in La Jolla. The 20 participants made their recommendations to NASA last week. It "makes sense", said the study's leader David McKay, a geologist at Houston's Johnson Space Center, for the space agency to consider using lunar materials for carrying out its future space missions. Whenever pioneers have ventured onto new territories, Dr McKay said, the first thing they do is use local materials.

If astronauts go to the Moon after a space station is finished, the study group said, they will inevitably start to become more self-sufficient and to rely less on communication with the Earth. Thus it is not too early to think about planning a space programme that relies on resources found in space.

The group, half of whose members had no previous association with NASA, was not, however, unanimous in this conclusion.

Proponents of the space resources scenario foresee the Moon and the asteroids as "gas stations" in the sky. The Moon, they note, is half oxygen which can be extracted and liquefied. The asteroids are rich in water. Thus rocket propellant liquid hydrogen and liquid oxygen - is there for the taking. Unprocessed regolith can be thermally sintered for bricks, tiles and pipes. Carbonyl chemical processing could turn out iron alloys. A solar furnace could cook up glass, ceramics, metals and three kinds of cement.

Critics of this scenario rested their case on economics. "A lunar base is a deadend", said Rocco Pazzolare of the Univer- sity of Arizona. "It's silly to put Manhattan on the Moon", said William Lewis of Clemson University.

The Earth is a water planet, Dr Fazzolare said. It is abundant in hydrogen and oxygen. The problem, he said, is not to figure out how to mine the Moon but how to get resources out of the Earth's gravity for less cost. Thus, he and others proposed that the American space effort should focus on "Big Dumb Boosters"' to lift more material into orbit more cheaply.

The third group is working within NASA to analyse the many suggestions coming its way. The direction the space programme

will take after the space station, they note, will affect how the station should be built As the station is now on the drawing board, planners want to know what comes next.

At the La Jolla meeting, there were three reasons given for US space efforts - fear, greed and curiosity. The fear people said the Soviet Union might get ahead of the United States and that is reason enough to go. An expert on space law pointed out that American interpretation of space treaties says that whoever gets to the Moon first will have the biggest say in how it is used. The greed people said continued commercialization is inevitable and that it ought to drive NASA's engines. Information is already big business and materials processing is soon to follow.

Sandra Blakeslee

\title{
Small space platforms favoured
}

\section{Washington}

A SCIENTIFIC advisory panel has strongly urged the National Aeronautics and Space Administration (NASA) to drop plans for including two large orbiting platforms as part of the design of the proposed space station (see above). The Task Force on Scientific Uses of Space Station recommended instead that NASA should develop a fleet of small platforms that could be tailored to the needs of individual experiments. Separate platforms could be pointed in different directions and would avoid the problems of interference and vibrations caused by combining many experiments on a single large platform.

The task force's recommendations come just one month before NASA is due to issue its request for proposals for an initial design and definition study for the space station. Dr Burton Edelson, associate administrator of NASA for space science and applications, assured the task force that its views would be taken seriously.

NASA is known, however, to favour the concept of two large platforms; John Hodge of the space station programme told the task force that the large platforms would offer a more "unified" approach to the station programme and would also be well suited to commercial projects, such as materials processing in space. One idea is to have one of the platforms orbit along with the station while the second travels in a polar orbit.

The official estimate of the cost of the space station is $\mathbf{\$ 8 , 0 0 0}$ million. Task force members have suggested, however, that if the cost of scientific instrumentation and of launching the station are included, the true figure approaches $\$ \mathbf{1 8 , 0 0 0}$ million. Congress has so far appropriated only $\mathbf{\$ 1 5 5}$ million, for the initial design work.

Other recommendations from the scientific task force include the construction of a "garage" within the station that could be used to assemble and repair satellites; construction of a separate module in the station for animal housing for experiments; and expanding to 10 the proposed 6-8 man capacity of the station to allow for six scientists.

The chairman of the task force is Dr Peter Brinks of Stanford's electrical engineering department.

Stephen Budiansky

\section{Voodoo on the campus}

\section{Washington}

FOR those who have forgotten that medicine is a young science, the University of Virginia is sponsoring a seminar this week featuring Dr Reinhold Voll, a German physician and the inventor of "electrodermal diagnosis" (EDD). According to Dr Voll, EDD can detect "chronic and terminal disease" by measuring skin resistance. A device, called the EAV Dermatron, is used to probe one of 850 acupuncture points on the skin that correspond to various internal organs, according to Voll, who has based his technique on traditional Chinese medicine.

The seminar is being held by the medical school's Health Information Center, which, in announcing the seminar, felt compelled to include a modest disclaimer:
"Admittedly, some of Dr Voll's claims sound rather speculative to Western scientific thought, such as the assertion of a direct relationship between acupuncture points and specific anatomical structures and physiological body functions, or EDD's ability to test the efficacy and tolerance of medication prior to its prescription. But then wasn't it scientific speculation which led to the development of the telephone, light bulb, television, laser and transistor, to name but a few inventions in our time?"

No double-blind trials have yet been carried out on the technique. Physicians attending the seminar are, however, encouraged to bring along patients with "well established or uncertain diagnosis" to test it out.
Stephen Budiansky 